\title{
Changes of the Students' Truth-Seeking Behaviour during the Infusion Mathematics Learning
}

\author{
Dian Kurniati ${ }^{1}$, Purwanto Purwanto ${ }^{2}$, Abdur Rahman As'ari ${ }^{2}$, Cholis Sa'dijah ${ }^{2}$ \\ ${ }^{1}$ University of Jember, JL. Kalimantan No 37, Jember, Indonesia \\ ${ }^{2}$ State University of Malang, JL. Semarang No 5, Malang, Indonesia
}

\begin{abstract}
Most students of mathematics education do not have truth-seeking. Therefore, it is necessary to do a corrective action in learning mathematics that can accustom students to tend to behave truth-seeking. The aim is to describe changes of students after the application of knowledge that accustoms truth-seeking through infusion mathematics learning. The research subjects were 25 students who were not truth-seekers at the beginning but experienced a change in the behavior of truth-seeking after the application of infusion learning. The data were collected through tests, direct observations, and interviews. The finding was that students experienced changes in truth-seeking behavior after participating in infusion learning for $\mathbf{1 0}$ meetings. This change was a habit that participants always do in response to a given mathematical problem.
\end{abstract}

Keywords - theory of planned behavior, truthseeking, infusion mathematics learning, problems with contradictory information.

\section{Introduction}

Critical thinking is a skill that must be possessed by everyone. That is because critical thinking is a predictor for one's success in the future [1]. Therefore, the Government of Indonesia stipulates

DOI: $10.18421 /$ TEM94-52

https://doi.org/10.18421/TEM94-52

Corresponding author: Dian Kurniati,

University of Jember, JL. Kalimantan No 37, Jember,

Indonesia

Email: dian.kurniati@unej.ac.id

Received: 08 July 2020.

Revised: 26 September 2020.

Accepted: 11 October 2020.

Published: 27 November 2020.

(c) BY-NC-ND (C) 2020 Dian Kurniati et al; published by UIKTEN. This work is licensed under the Creative Commons Attribution-NonCommercial-NoDerivs 4.0 License.

The article is published with Open Access at www.temjournal.com that one of the goals of learning in schools to tertiary institutions is to develop and familiarize students with critical thinking [2]. Furthermore, critical thinking is one of the thinking skills, which is the output of 21 st-century learning to get students to think at a higher level [3]. Truth-seeking is the primary behavior that must be possessed by someone who thinks critically. That is because the characteristics of people who think critically when faced with problems are to think first and be careful before solving the problem by criticizing all the information in the question to make the right decision whether the question needs to be resolved or not [4], [5], [6]. Also, the results of truth-seeking activities can be used as a basis for other critical thinking behaviors, namely inference, interpretation, evaluation, and explanation [7].

The study traced the truth-seeking tendencies of students, especially in solving mathematical problems in Higher Education [8]. The results and findings are that most students of mathematics education at four State Universities in East Java, Indonesia do not have critical thinking behavior, especially truth-seeking in responding to mathematics problems. Besides, some studies state that the critical thinking disposition of mathematics students in general when solving math problems is classified as low category, meaning that the majority of mathematics students do not yet have a critical thinking disposition [9], [10], [11]. Based on the results of the above research, it can be concluded that mathematics students do not have the disposition of critical thinking, especially truth-seeking, when solving mathematical problems. Therefore, it is necessary to do a corrective action in learning mathematics that can accustom students to tend to behave truth-seeking in solving mathematical problems.

Corrective actions in learning mathematics must pay attention to the factors underlying mathematics students who have not behaved truth-seeking in responding to mathematics problems. Disposition of critical thinking, including truth-seeking, is an internal motivation to solve the issues and decision 
making that is influenced by behavioral desires [12]. Based on this opinion, the tendency to behave truthseeking is controlled by the wishes of the individual's behavior [13]. Therefore, the factors behind a person doing truth-seeking can be viewed from the theory of behavioral desire known as the Theory of Planned Behavior [14]. Based on the previous explanation, to find out why mathematical students are not accustomed to doing truth-seeking can be seen from their behavioral desires when faced with mathematical problems that require non-routine activities in its solution.

Furthermore, one's desire to behave is influenced by three factors, namely individual attitudes, subjective norms, and behavioral control [14]. However, no research examines the factors that underlie students not behaving truth-seeking in responding to problems, especially mathematics. So, research is needed to explore these factors in terms of the Theory of Planned Behavior.

If the factors underlying the students not doing truth-seeking are known, then learning can be determined by referring to these factors so that students are accustomed to doing truth-seeking in responding to mathematical problems. Learning methods that are designed must integrate the three factors that influence the desire to behave in truthseeking. Various learning methods can improve critical thinking disposition in mathematics learning, namely infusion of critical thinking disposition [15], truth-seeking learning models [16], teaching probability [17], guided discovery models and infusing higher-order thinking skill. However, in general, there are 4 (four) kinds of learning approaches that can be trained to students to get used to the disposition of critical thinking [18]. These approaches are (1) general approach, (2) infusion approach, (3) immersion approach, and (4) combined approach. A learning approach that tries to utilize learning content in specific subjects to accustom critical thinking dispositions and adapted to critical thinking disposition indicators is the infusion approach [18], [7]. Therefore, in this study, learning that is used to familiarize mathematics students with truth-seeking behavior in responding to math problems is an infusion approach that is integrated with the three factors that shape the desire to behave.

Based on the explanation above, there are three objectives in this study. First, it describes the factors that underlie students not behaving truth-seeking in responding to mathematical problems. Second, design learning that is appropriate to accustom students to act in truth-seeking. Third, describe the change in truth-seeking behavior during infusion learning that is integrated with the factors of desire to behave.

\section{Literature Review}

\section{Truth - Seeking}

Truth-seeking is one of the characteristics of the seven characteristics belonging to the disposition of critical thinking [19]. Truth-seeking is a person's habit of checking the truth of all information received to get the best understanding in deciding something that is believed to be accurate. The statement is in line with the statement that truth-seeking is a habit of always wanting the best knowledge of specific situations [19] and the truth-seeking scale targets disposition to seek the best knowledge in specific contexts, dare to ask questions, be honest and objective in conducting investigations [20]. Also, Ennis states that people who tend to do truth-seeking always (1) look for clear statements about their theories or questions, (2) look for or pay attention to arguments, (3) try to find the best information, (4) using credible sources and mentioning them, (5) looking for as much precision as possible justification for a material, and (6) trying to stay relevant at the main points [21].

The characteristics of people who have truthseeking behavior in general are (1) always want the best understanding, (2) strongly emphasizing evidence and reasoning even to things that have been recognized truth, (3) questioning the beliefs of someone who has been established, and (4) not ignoring important details [19], [5]. Furthermore, specifically, the characteristics of mathematics students having truth-seeking behavior in responding to mathematical problems are (1) checking the truth of all information in the question, (2) correcting and change an illogical problem into a logical problem, (3) find all information relevant to the problem, (4) be honest and objective in asking questions about the truth of the information [9]. Based on this, the truthseeking indicators in responding to mathematical problems in this study are (1) collecting information that is in the matter of both true and false, (2) questioning the truth of all the information in the problem, (3) checking the truth of information in the problem, (4) analyzing all the information in the problem whether the information is false or right based on evidence and logical reasoning and supported with concepts, facts, principles and procedures in mathematics, (5) evaluating all possible ideas by referring to evidence and valid argument in mathematics, and (6) making decisions on the results of assessments that have been created. Truth-seeking in this research is focused on when mathematics students check the truth of all the information in the problem, the relationship between information in the problems, and the relationship between the problem and all information. 


\section{Theory of Planned Behaviour}

One manifestation of truth-seeking activities is not just following the existing conventions but instead emphasizing evidence and logical reasoning in deciding things. Therefore, the truth-seeking process is closely related to the tendency of one's attitude and personal nature. That is because the quality and attitude of an individual is a relative disposition that continuously influences the various behaviors of that person [22], [13]. Disposition of a person can be observed from the response, or the answer is consistent with non-routine activities [23]. Therefore, in this study, truth-seeking mathematics students can be seen from their responses when solving nonroutine problems. Observed responses are motivated by three determinants of behavioral desire, namely individual attitudes, subjective norms, and behavioral control, known as the Theory of Planned Behavior [23]. The Theory of Planned Behavior with examples of the application of truth-seeking behavior in responding to mathematical problems can be seen in Figure 1.

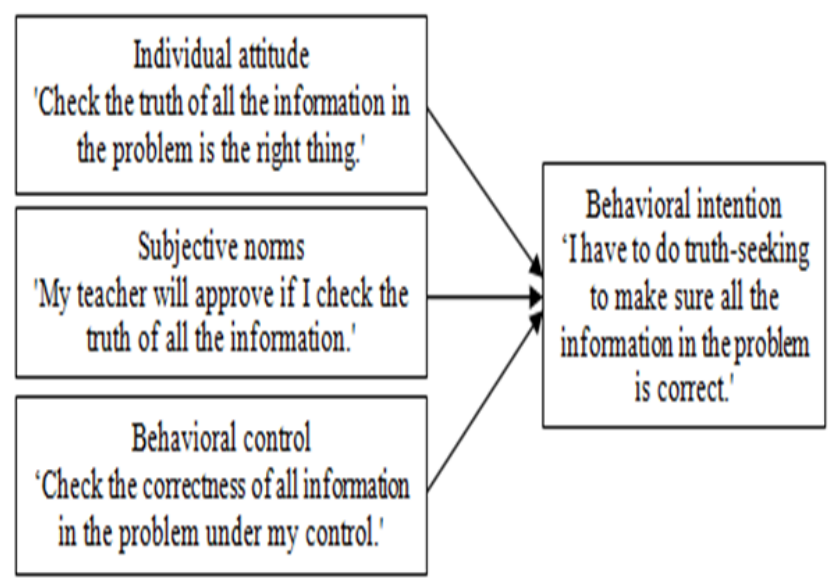

Figure 1. Theory of planned behavior with examples of the application of truth-seeking behavior in responding to mathematical problems

\section{Infusion Learning Approach}

An infusion approach is a learning approach that tries to utilize the learning content of individual subjects to familiarize students with a critical thinking disposition. When students learn certain material, for example, mathematics, students are asked to do critical thinking. In this case, the content of mathematics is a medium for learning to dispose of critical thinking, including truth-seeking behavior. According to Ennis, there are differences between the four teaching approaches that can be used to get into the habit of critical thinking [18]. The differences are as shown in Table 1.
Table 1. The General, mixed, infusion, and immersion approaches to teaching the critical thinking dispositions

\begin{tabular}{|lcccc||}
\hline $\begin{array}{l}\text { Make } \\
\text { General }\end{array}$ & General & Mixed & Infusion & Immersion \\
Principles & Yes & Yes & Yes & No \\
$\begin{array}{l}\text { Explicit? } \\
\text { Using }\end{array}$ & & & & \\
Content? & No & Yes & Yes & Yes \\
$\begin{array}{l}\text { Using Only } \\
\text { Standards }\end{array}$ & & & & \\
$\begin{array}{l}\text { Subject- } \\
\text { Matter }\end{array}$ & No & No & Yes & Yes \\
$\begin{array}{l}\text { Content? } \\
\text { Using }\end{array}$ & & & & \\
$\begin{array}{l}\text { Standard } \\
\text { Subject- }\end{array}$ & & & & \\
$\begin{array}{l}\text { Matter and } \\
\text { Other }\end{array}$ & No & Yes & Yes & No \\
Content? & & & & \\
\hline \hline
\end{tabular}

Based on Table 1., the infusion and immersion approaches can be equally applied to certain subjectmatter content such as mathematics. However, there is a difference between the two, if, in the infusion approach, the disposition of critical thinking is still guided and seen, while in the immersion approach, help, guidance, and encouragement from the teacher are no longer visible. The principles of critical thinking adjusted to the indicators of critical thinking disposition, in an infusion approach, are presented clearly. While in the immersion approach, these principles have not been revealed at all. So, in this study, the approach used is the infusion approach because at the learning stage explicitly asked students to get used to doing truth-seeking in responding to mathematical problems. The stages of learning follow the results of the search for factors that cause students not to do truth-seeking.

\section{Methodology of the Research}

\section{Research Design}

This research was a qualitative descriptive study because it describes in detail the factors behind mathematics students not doing truth-seeking and changing the truth-seeking behavior of students after an infusion learning action. Data on the elements of desire to behave and changes in truth-seeking behavior are based on direct observations and in accordance with the reality in the field. This is in line with the nature of descriptive qualitative research, namely qualitative data consisting of (1) a detailed description of the situation, people, interactions, and observed behaviors, (2) direct quotes from people about their experiences, attitudes, beliefs, and thoughts, and (3) excerpts or all parts of documents, correspondence, notes, and case histories [24]. 


\section{Research Subjects}

The research was attended by 40 students who had taken all mathematics courses in the Mathematics Education Study Program, Jember University, Indonesia. There were 25 out of 40 students selected as participants in the study with the provisions that (1) did not behave truth-seeking in responding to the first stage of mathematics problems, but experienced a change in the behavior of truth-seeking after the application of infusion learning, (2) had taken all mathematics courses, (3) agreed to be chosen as research participants, and (4) can communicate their thoughts through oral and written.

\section{Instruments}

There are 4 (four) instruments used in this study, namely test questions, observation sheets of truthseeking behavior, records, and interview sheets. Two experts in education and mathematics validated the four instruments. Based on the results of the validation, the contents of the four instruments were improved by referring to the advice of the two experts. First, the questions in this study were given as many as three questions that contained information that contradicted 1 question to determine participants and two other questions to see changes in truthseeking behavior during infusion learning. Second, the observation sheet of truth-seeking behavior is used as a tool to observe the tendency of truth-seeking behavior when solving a given problem. The indicators on the observation sheet refer to the 6 (six) truth-seeking indicators presented in the review of the literature. Third, the record referred to in this study is a recording of all activities both voiced or carried out by students in responding to questions. Fourth, the interview sheets used in this study are open but structured with the aim of finding out the factors behind students who do not behave truth-seeking in responding to mathematical problems.

\section{Data Collection Methods}

Data collection methods in this study were tests, direct observations, and interviews. The test was given in three stages, namely (1) the first stage was given to 40 students to determine participants in this study who were not truth-seekers, and (2) stages 2 and 3 were used to track changes in the truth-seeking behavior of students who were participants in the study this is during the application of infusion learning. Second, the method of direct observation is used to collect data relating to the tendency of truthseeking or not truth-seeking behavior in responding to a given mathematical problem. Third, the interview method is used to collect data relating to the factors behind the students not doing truth-seeking in responding to the questions given.

\section{Data Analysis}

In this study, there are 6 (six) stages of the data analysis process. The six data analysis processes are carried out by steps (1) transcribing collected verbal data, (2) analyzing all available data from various sources, namely from observing truth-seeking behavior, interviews, and the results of test questions, (3) conducting data reduction by selecting and focusing on search results not behaving truth-seeking along with the underlying factors, (4) compiling data in units which are further categorized by making coding based on the tendency of truth-seeking behavior, (5) determining research participants who are not truth-seekers, the factors underlying not behaving truth-seeking, determining appropriate learning methods to allow students to act truthseeking, and (6) making conclusions.

\section{Procedures}

There are six procedures in this study, first, giving questions to 40 semester VII students who have taken all mathematics courses. During the completion of the first phase of the problem, the researcher directly observed the truth-seeking behavior carried out by 40 mathematics students with the help of a recording tool. Based on the results of the recording, data was obtained on the tendency of student behavior that does not do truth-seeking in responding to the first problem. Second, the determination of research subjects that are not truth-seekers from 40 students and the third procedure is the search for the factors underlying the research subjects who do not behave truth-seeking in responding to the questions given. Fourth, the determination of the stages of infusion learning to familiarize the truth-seeking behavior of the research subject based on the factors underlying the research subject who are not truth-seekers. Fifth, observing changes in truth-seeking behavior of research subjects who initially were not truth-seekers during the process of applying infusion learning. Sixth, making conclusions to answer research questions.

\section{Results of the Research}

\section{Factors that Cause Truth-Seeking Behavior}

The participants in this study were 34 mathematics students who did not do truth-seeking in responding to the math problems given. The math problem given was a problem with contradictory information as shown in Figure 2. 


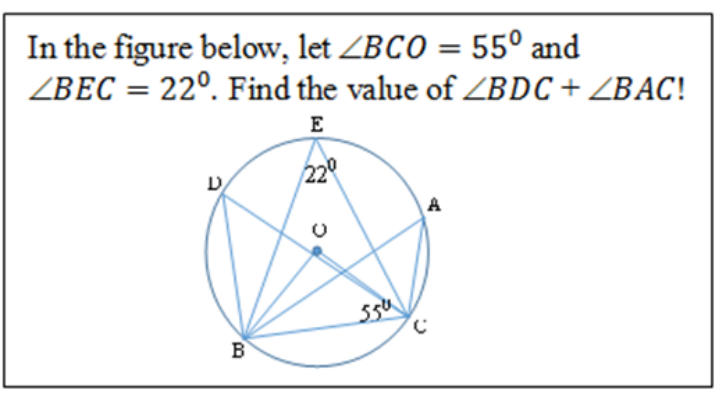

Figure 2. The problem with the contradictory information

The tendency of the initial responses made by 34 students is (a) mentioning all the information in the problem, (b) not questioning the truth of the information in the problem, (c) not checking the truth of the information given to the problem before trying to solve the problem, and (d) directly work on the given problem and determine the solution of the problem. Such behavior is not a characteristic of people who are truth-seekers when facing a given problem.

Based on observations, interviews, and answer sheets written by 34 students who are the subjects in this study, there are three groups of answer trends and factors that cause students not to do truth-seeking. The first, second, and third groups consist of 10, 15, 9 students, respectively. First, the ten students gave the same response to the questions presented, in Figure 3.
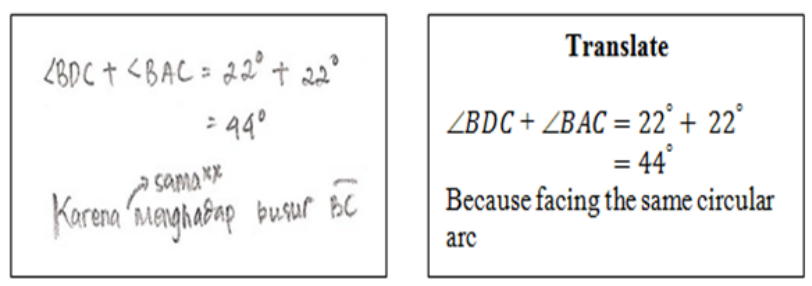

Figure 3. Written answers 1 in 10 first group research subjects

In Figure 3., it can be seen that the research subject directly works on the given problem without checking the truth of the information known to the problem. The stages of the process are (a) determine that $\angle \mathrm{BDC}, \angle \mathrm{BAC}$, and $\angle \mathrm{BEC}$ are the circumferential angles facing the same arc, namely $\widehat{B C}$ so that the angles are the same, namely $m \angle \mathrm{BDC}=m \angle \mathrm{BAC}=$ $m \angle \mathrm{BEC}=22^{\circ}$, (b) not comparing the magnitude of the circumferential angle $(m \angle \mathrm{BDC}, \mathrm{m} \angle \mathrm{BAC}$ and $m \angle \mathrm{BEC}$ ) with the magnitude of the central angle ( $m \angle \mathrm{BOC}$ ) facing the same arc, i.e., $\widehat{B C}$, and (c) not checking the correctness of the central angle ( $m \angle \mathrm{BOC})$ by comparing $(\mathrm{m} \angle \mathrm{BOC})$ when viewed from the properties of the isosceles triangle $\triangle B O C$ with $m \angle B O C$ when viewed from the relation of the large central angle and the magnitude of the circumferential angle facing the same arc. Therefore, the ten students answered the question with a direct answer which is $m(\angle \mathrm{BDC}+\angle \mathrm{BAC})=22^{\circ}+$ $22^{\circ}=44^{\circ}$.
The ten research subjects are accustomed to solving problems without checking the truth of all known information. Based on the interview results, they were not suspicious of incorrect information or contradiction. The reason was because the participants did not find the problem given by the lecturer was a wrong problem. If there are wrong questions, usually the teacher of the course tells that the items given are incorrect and provides an improvement. Therefore, they always believe that the questions given by the teacher are the correct questions. Based on the theory of desire to behave, the factors underlying the ten students who are not accustomed to truth-seeking in responding to the questions given are (a) the teacher in their place of study has not accustomed students to dispose of critical thinking, (b) the questions commonly given during the study are questions that are routine and do not require students to share critical thinking, (c) students' belief in the thought that the questions given by the teacher are always correct.

Second, 15 students also directly worked on the questions given without checking the truth, as did the other ten students in the first group. Fifteen students answered the questions given with the same response, as presented in Figure 4.

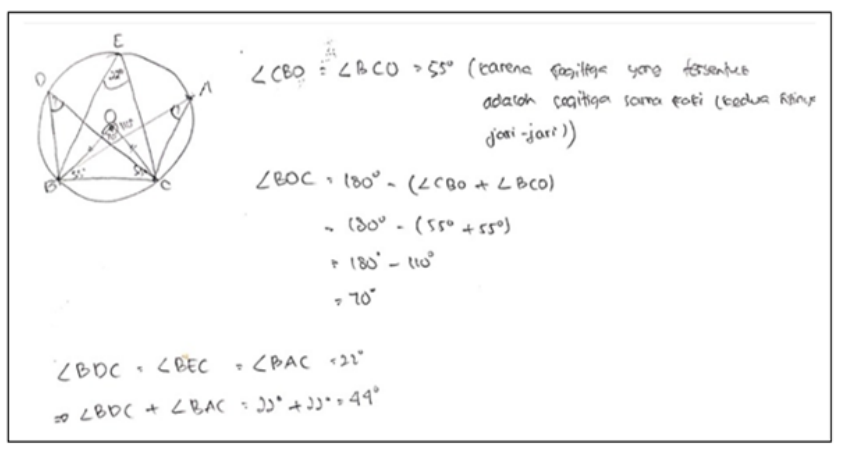

\begin{tabular}{|c|}
\hline 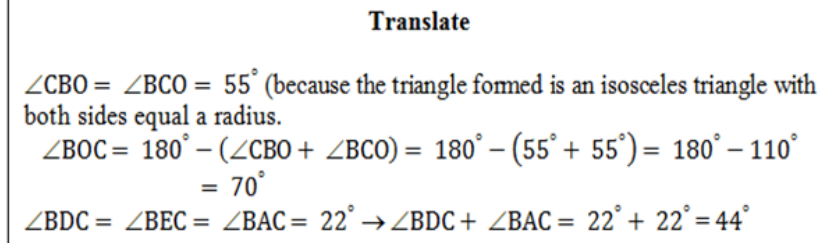 \\
\hline
\end{tabular}

Figure 4. Written answers 1 in 15 second group research subjects

The stages of problem-solving carried out by 15 students differed from the first ten students in the first group, which initially determined $m \angle \mathrm{CBO}=$ $m \angle \mathrm{BCO}=55^{\circ}$ by applying the properties to the environment. The next stage is determining $m \angle \mathrm{BOC}$ by applying the concept of an isosceles triangle so that $m \angle \mathrm{BOC}=180^{\circ}-(m \angle \mathrm{CBO}+m \angle \mathrm{BCO})=$ $70^{\circ}$. However, 15 research subjects did not continue the process of determining the solution of $m \angle \mathrm{BDC}+$ $m \angle \mathrm{BAC}$ by applying the results obtained previously 
namely $m \angle \mathrm{BOC}=70^{\circ}$, but instead, they determined $m \angle \mathrm{BDC}+m \angle \mathrm{BAC}$ by using the characteristics of the circumferential angles facing the same bow. So, we get $m \angle \mathrm{BDC}+m \angle \mathrm{BAC}=22^{\circ}+22^{\circ}=44^{\circ}$ because $m \angle \mathrm{BDC}=m \angle \mathrm{BEC}=m \angle \mathrm{BAC}=22^{\circ}$.

Based on the results of interviews of researchers with 15 research subjects, the factors underlying 15 research subjects have in common with the other ten subjects that they assume that all questions are always correct. However, there are two other factors underlying 15 research subjects not doing truthseeking in responding to the given problem, namely (1) poor understanding of the concept of the central angle and the circumferential angle of the circle facing the same arc, (2) accustomed to working on the problem without determining the right strategy before starting to solve the problem, and (3) assume that all information known in the problem is always used to solve the question being asked so that they solve the problem given in two conflicting stages.

Third, nine research subjects also have the same tendency with the 25 other subjects, namely not doing truth-seeking in responding to mathematical problems. However, the nine research subjects had suspicions about the answers they wrote. They doubt the answers they write because there are differences between the results with the facts in the problem. Although all nine subjects had doubts about the answers they wrote, they did not try to double-check all the information in the problem. The answers are written by the nine subjects, in Figure 5 .

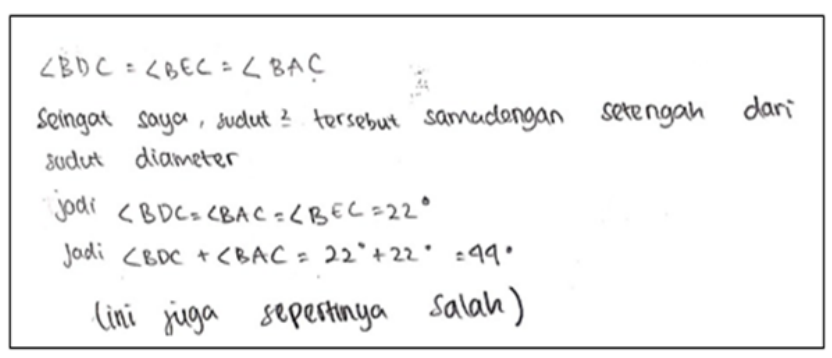

\begin{tabular}{l} 
Translate \\
$\angle \mathrm{BDC}=\angle \mathrm{BEC}=\angle \mathrm{BAC}$ \\
The angles are equal to half of the diameter angle \\
So $\angle \mathrm{BDC}=\angle \mathrm{BEC}=\angle \mathrm{BAC}=22^{\circ}$ \\
So $\angle \mathrm{BDC}+\angle \mathrm{BAC}=22^{\circ}+22^{\circ}=44^{\circ}$ (this seems wrong) \\
\hline
\end{tabular}

Figure 5. Written answers 1 in 9 third group research subjects

The stages of working on the problems performed by the nine subjects have in common with the ten subjects in the first group, applying the concept of the circumferential angle to the circle facing the same arc. Thus, $\angle \mathrm{BDC}=\angle \mathrm{BEC}=\angle \mathrm{BAC}=22^{\circ}$ and this results in that $\angle \mathrm{BDC}+m \angle \mathrm{BAC}=22^{\circ}+22^{\circ}=44^{\circ}$. However, the nine subjects were suspicious that it seemed that their work process had been mistaken because they stated that the actual circumferential angle of the circle was half the center angle. The nine students did not try to double-check the information that was known, because they thought that it was impossible that the problem given was wrong. They stated that the questions given by the teacher were always right, and they were not accustomed to solving the questions that demanded to have a critical thinking disposition.

Referring to the results explained above, if viewed from the Theory of Planned Behavior, the factors underlying the subject of research do not do truthseeking in responding to the questions given are as follows.

1. individual attitude: assume that the questions given by the teacher are always right, so there is no need to check the truth of the information on the questions,

2. Subjective norms: (a) teachers who do not accustom students to critical thinking especially truth-seeking; (b) the questions given during the lesson are routine and do not require students to think critical thinking,

3. Behavioral control: (a) poor understanding of concepts, (b) accustomed to working on the problem without determining the right strategy before starting to solve the problem, and (c) assume that all information known in the problem is always used to solve the question being asked.

\section{Infusion Learning to Familiarize Truth - Seeking Behavior}

Based on the factors underlying the research subject not doing truth-seeking, it can be arranged for infusion learning design to familiarize truth-seeking behavior when responding to mathematical problems. The infusion learning design is focused on the practice of giving questions that accustom students to truth-seeking behavior in one of the 5th-semester courses, namely Real Analysis. The questions that are designed are questions that contain contradictory information so that the mindset is formed that not always the questions given by the teacher are the correct questions. So, students always suspect that the questions given by teachers are likely to be wrong and need to be checked for truth before the problem is done.

In addition to designing questions with contradictory information, infusion learning is applied during ten meetings on the subject of the nature of algebra and the ordered nature of real numbers in the Real Analysis course, which is attended by 34 students as research subjects. The reason for the determination of 10 meetings is because in the lecture design, ten meetings are conducted on the algebraic 
and order properties of real numbers. The questions given during infusion learning and at the end of determining the change in truth-seeking behavior relate to the nature of algebra and the ordered nature of real numbers. At each meeting, the lecturer adviser of the course gives questions with contradictory information and routine questions, so students are accustomed to the lecturer concerned always asking students to think critically, especially truth-seeking, in responding to real analysis questions. Each learning meeting, two questions are given with contradictory information, and one routine question is at the end of the lesson. In addition to giving questions with contradictory information, the lecturer also asks students always to double-check the answers they have found. After ten infusion learning meetings were conducted, all subjects were asked to solve two questions with contradictory information to determine whether there was a change in truth-seeking behavior in themselves. The two questions are as follows.

1. Given $x, y, z \in R$, with $x^{3}=6, y^{2}=-2$ and $z=4$. Find the value of $x^{6}+y^{4}-z^{2}$ !

2. Given $x+3 y+7 z=50$ with $x=2 k+1$, $y=2 l+1, \quad$ and $z=2 m+1$, with $k, l, m \in N$ and $N$ is a natural number. Find the value of $x, y$, and $z$ !

The next design relates to the strengthening of concepts in the Real Analysis course so that the concepts of the students develop optimally. Consolidation of concepts can be done by asking students to study material at home and present materials or questions that are not yet understood. Finally, through infusion learning in the Real Analysis course, students are expected to get used to being more careful in solving problems and accustomed to understanding information known to the questions given.

\section{Change in Truth - Seeking Behavior}

After the infusion learning activities in the 10course Real Analysis course, a trend of seeking truthseeking behavior from 34 students was conducted. There were 25 students who initially were not truthseekers turned into truth-seekers students in responding to mathematics problems, while nine other students were still not accustomed to truthseeking. The nine students tend not to behave truthseeking because of their weak understanding of the material about the ordered nature of real numbers. So, out of 10 meetings, four times checked the truth, and six other sessions did not do truth-seeking in responding to the questions. However, the mindset about questions is always right in the nine students' changing, so they believe that questions from lecturers are not still right.
After participating in infusion learning in the Real Analysis course, 25 students who were not truthseekers initially experienced a change in that they tended to behave truth-seeking in responding to each question given during the study and two questions at the end of the meeting. As for the changes made by 18 out of 25 students when responding to the two questions given, they said that "this problem can also be wrong and cannot be done like the previous questions, so I must check the truth of the information about this question before working on the question." In addition, seven other students tend to be consistent from the start of infusion learning, which always says that "I have to check all the information, there may be incorrect information or excessive information to solve this problem, so I am sure that my answer is correct." There are similarities in the stages of checking the truth by 25 students who are truthseekers in responding to the first problem, one of their answers, shown in Figure 6.

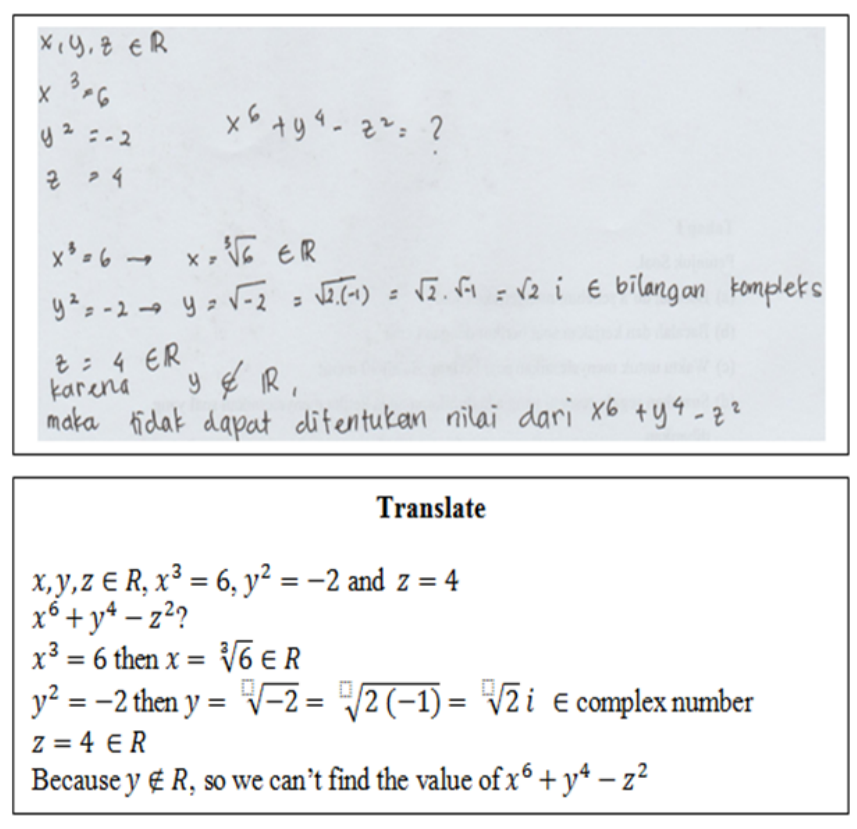

Figure 6. Written answer 1 of 25 research subjects in response to first question

Based on Figure 6., the stages of truth-seeking conducted by 25 research subjects are as follows.

1. Determine the values of $x, y, z \in R$, which qualify that $x^{3}=6, y^{2}=-2$, and $z=4$. If $x \in R$ and $x^{3}=6$ then $x=\sqrt[3]{6}$. If $y \in R$ and $y^{2}=$ -2 , then the value of $y$ cannot be satisfied because the value of $y$ obtained is a complex number instead of a real number. If $\in R$ and $z=4$, then $z=4$.

2. Analyze the results found for the values $x, y, z$. The student states that there is one contradictory information in the problem, namely that $y \in$ $R$ and $y^{2}=-2$. So, it can be concluded that the problem given is the wrong question. 
3. They are making the decision not to continue the process of solving the problem because the given problem is wrong so that the value of $x^{6}+y^{4}-$ $z^{2}$ cannot be determined.

Furthermore, there are similarities in the stages of truth checking conducted by 25 research subjects in response to the second question. After they want to check the truth of information based on previous experience during infusion learning, they begin to verify the truth by analyzing any known information. As for the truth checking stage carried out by 25 subjects in response to the second problem, shown in Figure 7.

Based on Figure 7., the truth-seeking stage carried out by 25 research subjects; namely, analysis begins with determining that the numbers $x, y, z$ are odd numbers because $k, l, m \in N$ and $x=2 k+1$, $y=2 l+1$, and $z=2 m+1$. Furthermore, 25 subjects determine that the numbers $3 y$ and $7 z$ are odd numbers because $y$ and $z$ are odd numbers. The next stage is the subject of the study stating that "the addition of 3 odd numbers produces odd numbers too, so it is not true that $x+3 y+7 z=50$ because 50 is not an odd number". Based on the results of the analysis, 25 subjects concluded that the second question was the wrong question so that the solution to the problem could not be determined. Therefore, 25 research subjects did not continue the process of problem-solving because there was contradictory information.

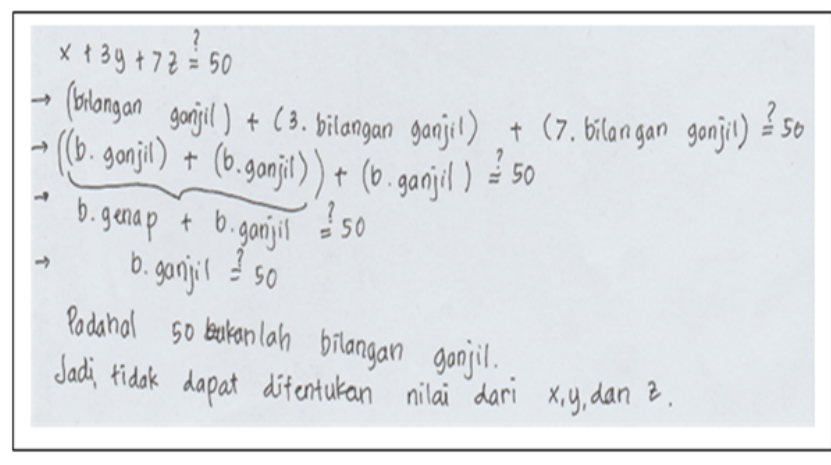

Translate
$x+3 y+7 z \stackrel{?}{=} 50$
$\rightarrow$ (odd number $)+(3$ odd number $)+(7$ odd number $) \stackrel{?}{=} 50$
$\rightarrow$ (odd number + odd number $)+$ odd number $\stackrel{?}{=} 50$
$\rightarrow$ even number + odd number $\stackrel{?}{=} 50$
$\rightarrow$ odd number $\stackrel{?}{=} 50$
50 isn't an odd number, so we can find the value of $x, y, z$

Figure 7. Written answer 1 of 25 research subjects in response to the second question

Based on the results of the study discussed earlier, the findings in this study are detailed in Figure 8.

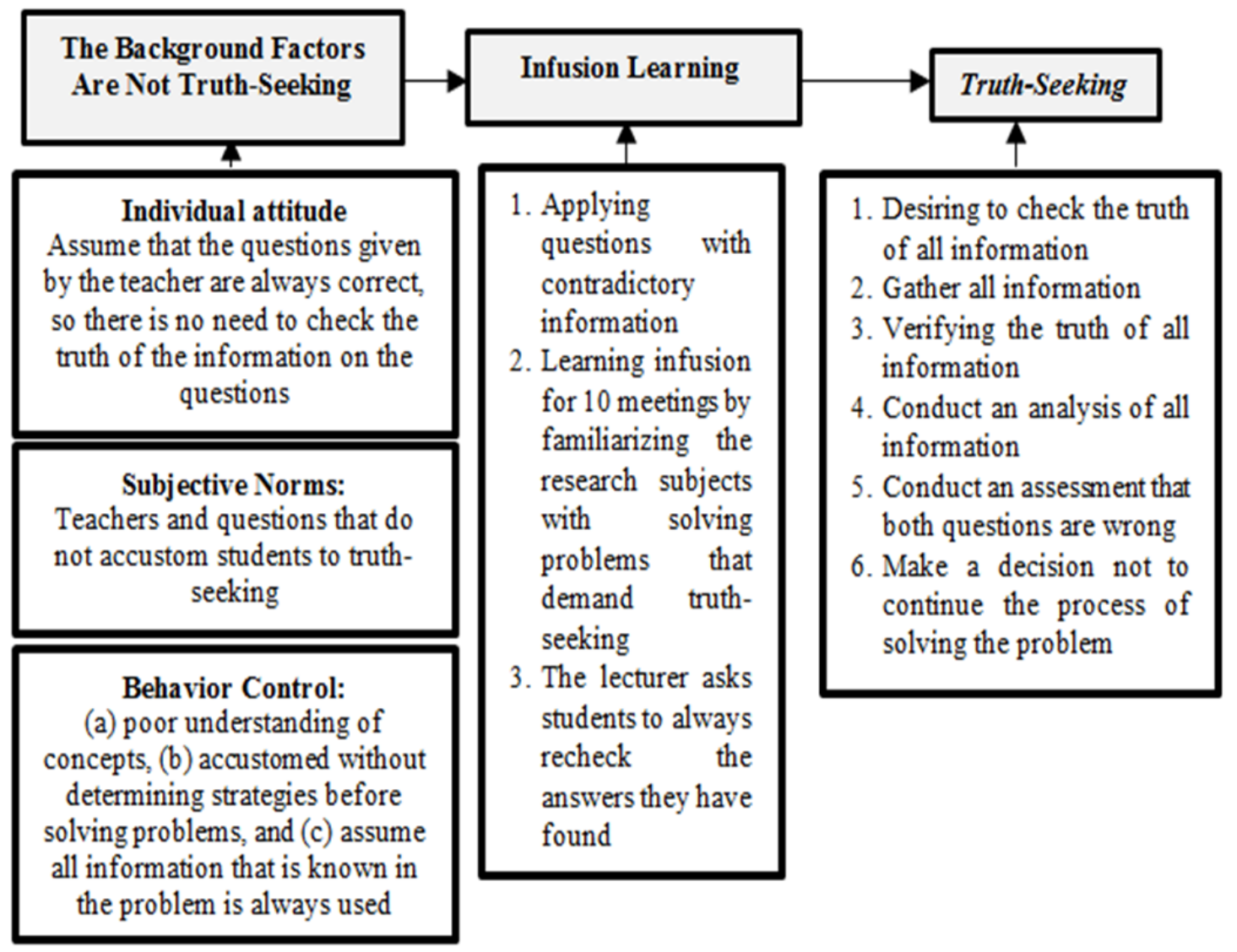

Figure 8. Research findings 


\section{Discussions}

The results of this study indicate that 25 students experienced changes in truth-seeking behavior in responding to mathematical problems after participating in truth-seeking infusion learning that applied questions with contradictory information. The change experienced by 25 of 34 students was at the beginning of giving a math problem that did not behave truth-seeking to become accustomed to doing truth-seeking in responding to a math problem. Their habits in responding to mathematics problems are outputs of truth-seeking infusion learning activities. Therefore, infusion learning can familiarize students with critical thinking propositions, especially truthseeking. This is in line with the opinion, which states that infusion learning can familiarize students with truth-seeking and open-mindedness in solving math problems [7]. In addition, Ennis also states that infusion learning is one of four other learning that can accustom someone to think critically [18].

The infusion learning applied in this study is integrated with the provision of questions containing contradictory information. Problems with contradictory information are valid and reliable types of questions to measure and accustom students to truth-seeking before solving math problems [25]. Based on the results of the study, when 25 students in this study were suspicious of excessive information on questions that contained contradictory information, they directly checked the truth of all information contained in the questions. This is in line with the results of the research, which states that skepticism or suspicion are behaviors that underlie and motivate someone to think reflective and critical thinking [8]. Therefore, the suspicion of 25 students in this study of information that is known in the matter makes them want to check the truth of all information.

The subjects in this study were suspicious of the information in the problem because, during the truthseeking infusion study in Real Analysis, they believed that in mathematics, there were facts or definitions that did not need to be verified, and there were also theorems or axioms that had to be verified. In addition, they also have the intuition that the statement in the problem is a statement that is not clear and must be proven true to be accepted. These activities are formal cognitive-based activities that relate to one's intuition when solving mathematical problems [26]. Therefore, mathematics students who do this can be said to have critical thinking dispositions, especially truth-seeking. This is in accordance with the opinion, which states that a person is said to have a critical thinking position if the person does not necessarily receive all the information provided without any effort to gain confidence in the truth of the information [27]. Based on this, the skepticism that begins with suspicion of all the information in the problem is an important aspect of the disposition to familiarize prospective mathematics teachers with truth-seeking behavior.

The desire of 25 research subjects to do truthseeking in responding to questions with contradictory information is a routine habit that they do during the application of infusion learning in class. So, at the end of the meeting, the 25 students conducted truthseeking in responding to 2 questions given by the lecturers of the Real Analysis course. Truth-seeking behavior in responding to problems with contradictory information by research subjects during infusion learning can be said to be a habit of thinking, a set of dispositions that are learned and practiced before someone can complete a task [28] where the disposition is carried out on an ongoing basis [28]. Trends in truth-seeking behavior conducted by mathematics students in this study are in accordance with one of the 16 dispositions belonging to the category of thinking habits, according to Costa \& Kallick, namely controlling impulsivity [28]. Controlling impulsivity means being able to refrain from impulsivity, namely behavior, to be more careful in solving problems by trying to understand the problem well, determining the right strategy, and considering all alternatives to determine information relevant to the problem [27].

\section{Conclusions}

The conclusion of this research is that there is a change in the tendency of behavior by students in responding to mathematical problems. The change is that initially, students do not behave truth-seeking in responding to math problems, but after applying infusion learning in the Real Analysis course with algebraic nature and sequential properties of real numbers during ten meetings, the tendency of student behavior is to check the truth of the information in the problem. Thus, truth-seeking behavior becomes a habit that students have in responding to mathematical problems. The infusion learning design applied in this study refers to the factors that underlie students not behaving truth-seeking at the beginning of giving a question. The factors are (1) individual attitude: assume that the questions given by the teacher/lecturer are always correct, so there is no need to check the truth of information on the questions, (2) subjective norms: lecturers and questions that do not accustom students to truth-seeking, and (3) behavioral control: (a) poor understanding of concepts, (b) accustomed without determining strategies before solving problems, and (c) assume all information that is known in the problem is always used. 


\section{Acknowledgements}

The researchers would like to express their gratitude to the Ministry of Reseacrh, Technology, and Higher Education of Republic of Indonesia, the Graduate Program of Mathematics Education at The State University of Malang, and the Department of Mathematics Education at The Faculty of Teacher Training and Education of University of Jember.

\section{References}

[1]. Akinoglu, O., \& Karsantik, Y. (2016). Pre-Service Teachers' Opinions on Teaching Thinking Skills. International Journal of Instruction, 9(2), 6176.

[2]. Kementerian Pendidikan dan Kebudayaan. (2016). Standar Kompetensi Lulusan Pendidikan Dasar dan Menengah [Competency Standards for Primary and Secondary Education]. Peraturan Menteri Pendidikan dan Kebudayaan Nomor 20, Indonesia.

Retrieved from:

https://bsnp-indonesia.org/wpcontent/uploads/2009/04/Permendikbud Tahun2016 Nomor020 Lampiran.pdf [accessed: 20 February 2020].

[3]. Kim, K. M., \& Md-Ali, R. (2017). GeoGebra: towards realizing $21 \mathrm{st}$ century learning in mathematics education. Malaysian Journal of Learning and Instruction, 93-115.

[4]. Ennis, R. H. (2011). The nature of critical thinking: An outline of critical thinking dispositions and abilities. University of Illinois, 2(4).

[5]. Facione, P. (2000). The disposition toward critical thinking: its character, measurement, and relationship to critical thinking skill. Informal Log 20: 61-84.

[6]. Cheng, M. H. M., \& Wan, Z. H. (2017). Exploring the effects of classroom learning environment on critical thinking skills and disposition: A study of Hong Kong 12th graders in Liberal Studies. Thinking Skills and Creativity, 24, 152-163.

[7]. As' ari, A. R., Kurniati, D., Abdullah, A. H., Muksar, M., \& Sudirman, S. (2019). Impact of infusing truthseeking and open-minded behaviors on mathematical problem-solving. Journal for the Education of Gifted Young Scientists, 7(4), 1019-1036.

[8]. Kurniati, D., \& Purwanto, A. A. AR, \& Dwiyana (2019). The Truth-Seeking and Open-Mindedness of Pre-Service Mathematics Teachers in the Solution of Non-Routine Problems. International Journal of Instruction, 12(1), 915-930.

[9]. Alper, A. (2010). Critical thinking disposition of preservice teachers. Egitim ve Bilim, 35(158), 14.

[10]. Biber, A. C., Tuna, A., \& Incikabi, L. (2013). An investigation of critical thinking dispositions of mathematics teacher candidates. Educational Research, 4(2), 109-117.

[11]. Yorganci, S. (2016). Critical Thinking Dispositions of Pre-Service Mathematics Teachers. Online Submission, 3(3), 36-46.
[12]. Facione, P. (1990). Critical thinking: A statement of expert consensus for purposes of educational assessment and instruction (The Delphi Report).

[13]. Ajzen, I. (1987). Attitudes, Traits, and Actions: Dispositional Prediction of Behavior in Personality and Social Psychology. Advanced in Experimental Social Psychology, 20, 1-63.

[14]. Ajzen, I. (1991). The theory of planned behavior. Organizational behavior and human decision processes, 50(2), 179-211.

[15]. Darby, N. M., \& Rashid, A. M. (2017). Critical Thinking Disposition: The Effects of Infusion Approach in Engineering Drawing. Journal of Education and Learning, 6(3), 305-311.

[16]. Ansori, A. Z., Ibrahim, M., \& Widodo, W. (2017, August). Theoretical Study of the A Truth-Seeking Learning Model: The Learning Model to Improve Students' Critical Thinking Disposition. In 1st Annual International Conference on Mathematics, Science, and Education (ICoMSE 2017). Atlantis Press.

[17]. Aizikovitsh-Udi, E., \& Cheng, D. (2015). Developing critical thinking skills from dispositions to abilities: mathematics education from early childhood to high school. Creative education, 6(04), 455.

[18]. Ennis, R. H. (1989). Critical thinking and subject specificity: Clarification and needed research. Educational researcher, 18(3), 4-10.

[19]. Insight Assessment . (2013). California critical thinking disposition inventory (CCTDI). San Jose, CA: The Californian Academic Press.

[20]. Facione, P. A., Sanchez, C. A., Facione, N. C., \& Gainen, J. (1995). The disposition toward critical thinking. The Journal of General Education, 44(1), 125.

[21]. Ennis, R. H. (1985). A logical basis for measuring critical thinking skills. Educational leadership, 43(2), 44-48.

[22]. Sniehotta, F. F., Presseau, J., \& Araújo-Soares, V. (2014). Time to retire the theory of planned behaviour. Health psychology review, 8(1), 1.

[23]. Ajzen, I. (2012). The theory of planned behavior. Handbook of Theories of Social Psychology, 1 (1): 438-459.

[24]. Sherman, R. R., \& Webb, R. B. (2005). Qualitative Research in Education: Focus and Methods.

[25]. King, P. M., \& Kitchener, K. S. (1994). Developing Reflective Judgment: Understanding and Promoting Intellectual Growth and Critical Thinking in Adolescents and Adults. Jossey-Bass Higher and Adult Education Series and Jossey-Bass Social and Behavioral Science Series. Jossey-Bass, 350 Sansome Street, San Francisco, CA 94104-1310.

[26]. Fischbein, E. (1999). Intuitions and schemata in mathematical reasoning. Educational studies in mathematics, 38(1-3), 11-50.

[27]. Bakir, S. (2015). Critical thinking dispositions of pre-service teachers. Educational Research and Reviews, 10(2), 225-233.

[28]. Alhamlan, S., Aljasser, H., Almajed, A., Almansour, H., \& Alahmad, N. (2018). A Systematic Review: Using Habits of Mind to Improve Student's Thinking in Class. Higher Education Studies, 8(1), 25-35. 